\title{
Erratum to: Properties of recombinant Strep-tagged and untagged hyperthermophilic D-arabitol dehydrogenase from Thermotoga maritima
}

Verena Kallnik • Christian Schulz • Paul Schweiger •

Uwe Deppenmeier

Published online: 15 April 2011

(C) Springer-Verlag 2011

Erratum to: Appl Microbiol Biotechnol

DOI 10.1007/s00253-011-3187-5

The original version of this article, unfortunately, contained a mistake. The name of the second author should have been Christian Schulz instead of Christian Schultz.

The online version of the original article can be found at http://dx.doi. org/10.1007/s00253-011-3187-5.

V. Kallnik $\cdot$ C. Schulz $\cdot$ P. Schweiger $\cdot$ U. Deppenmeier $(\bowtie)$ Institut für Mikrobiologie \& Biotechnologie, Universität Bonn, 168 Meckenheimer Allee,

53515 Bonn, Germany

e-mail: udeppen@uni-bonn.de 